\title{
Directed energy
}

\section{More than just a flash in the pan.}

\section{Jeff Hecht}

A buzzing sound startled Ellen so she spilled her tea. After years of fighting the spread of insect-borne diseases in a warming world, bugs scared her more than her brother Bernie's war machines.

"Are you okay, Sis?" Bernie asked. "You look jittery."

"I thought I heard a mosquito." She had felt something tickling her left ear earlier, but it had only been the naturally shed macaw feather attached to her new earring.

He chuckled. "You can't be so jumpy in defence work.

She frowned older-sibling disapproval at her errant brother ${ }^{\alpha}$ Controlling the spread of disease-carrying insects is a serious business, Bernie."

"So is defending against nuclear missiles."

"How many million people did they kill last year?"

"None, thanks to missile defence."

"Really, Bernie?" Ellen was eight years older, and after 52 years retained the wisdom of age. "How many nuclear missiles could your lasers really shoot down? You never even tested them."

"It's classified. I can't tell you."

That was his standard line. "It's classified because it doesn't work, and that's embarrassing, isn't it, Bernie?"

"It's a strategic defence system, Sis. It doesn't have to work every time. It's supposed to deter attack, so we only have to convince the other side that it could work.

"So it's all a bluff. I wish I could bluff mosquitoes away. Did anybody ever use anything you developed at Beltway Banditos?"

"The name was Beltway Systems," said Bernie, who had tired of the joke years ago. "Some of our technology has dual military and civilian uses. Remember that low-orbit satellite telephone system I told you about? The laser links between satellites used the pointing and tracking technology developed for our space-based laser interceptor."

"Did the phone satellites ever get off the ground?"

Bernie's face slumped, as it always did when one of his experiments went wrong, and he looked at the floor of his cluttered little house. ${ }^{\alpha}$ They laid me off before they finished the system, and I haven't checked.
Ellen signed. Bernie had spent 25 years in the defence industry, until the worsening climate crisis had finally drained the big money away from military hardware. "What are you working on now?"

Bernie's eyes brightened; he always liked to talk about his latest crazy idea. "I found more dual-use potential for the tracking and pointing technology. I've scaled it
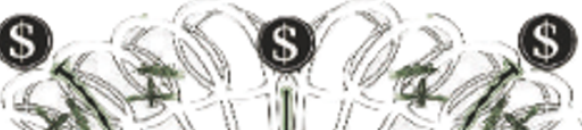
 e pointed at a series of little boxes, and explained their functions too fast for Ellen to follow. Then he flipped a switch. ZAP! A flash erupted in front of the box, and a little puff of smoke spread into the air. ZAP! Another flash. Except for his white hair and his middle-aged spread, Bernie could have been a 16-year-old playing with a new techno-toy. "Each zap takes out another bug. I can set it to pick out only certain species if you want, so it bags mosquitoes but not butterflies."

Ellen was speechless. Her brother had finally done something worthwhile. The little laser box could destroy incoming diseasecarrying insects without using pesticides or harming beneficial types. She could see thousands of the boxes in village squares around the world, blocking the spread of disease. "Incredible!" she said. "Simply incredible."

Bernie glowed with pride.

${ }^{\circ}$ How did you manage to scale everything down?"

"Not quite everything." Bernie looked thoughtful for a moment. "It takes a lot of sensors and computer power to track the bugs, but it's a lot cheaper than missile defence."

"Wonderful," Ellen said, nodding her head. She saw one of the little laser boxes point toward her. A ZAP sizzled near her ear. "Ouch," she said, putting her hand up and feeling her earring. "Bernie! You burnt the feather off my earring."

"It was moving; it must have fooled the sensors."

${ }^{\alpha}$ That was a naturally shed feather from an endangered species. I paid $\$ 70$ for it $]^{p}$

A familiar impish grin appeared on her brother's face. "We're still ahead. Each laser pulse costs only $\$ 50$.

Jeff Hecht writes regularly for New Scientist and Laser Focus World. His most recent book is Beam: The Race to Make the Laser. The match-head rocket he launched in his teens never set anything on fire. 